\title{
correspondence
}

\section{Accounts of East European science are reliable}

SIR, - Dr Lorch's attack on Vera Rich (13

September, page 98 ) is not only graceless: it is also futile. As many an obfuscating party bureaucrat knows to his chagrin, she is a tough and determined person who thrives on reckless abuse and has an uncanny facility for discovering awkward truths behind the glossy facades of of ficial science. In other words, she brings to the readers of Nature the bestintormed and most reliable account of science in Eastern Europe and the Soviet Union that is puilicly available in the Free World. In so doing, Ms Rich complements the correspondingly unsycophantic reports of Colin Norman and David Dickson from Washington, and the sober dispatches that you have recently been publishing from various countries in the Third World. Good work; keep it up.

For it is not by enthusiasm for intergovernmental research projects, nor by the exchange of vacuous academic courtesies between scientists of rival nations, nor by cheerful splurges about marvellous work being done in this or that country, that the pursuit of science will be safeguarded. The fundamental factor for the health of the world scientific community is solidarity in protecting the human rights of scientists of all countries.

I believe that most of my colleagues with recent first-hand knowledge of the state of science in many countries of the Socialist bloc would agree that the situation is very largely as Ms Rich describes it, and that this continues to be a matter of the gravest concern for us all. The information that you thus make public in Nature is not only essential for those who would combat such evils: it is, by its very publication, of immense influence. Yours faithfully,

University of Bristol, UK

JOHN ZIMAN

\section{Doctor disappears in Afghanistan}

SIR, - I am writing on behalf of the staff of this department, to bring to the attention of our scientific and medical colleagues, difficulties we are having in communicating with a former colleague in the Faculty of

Medicine, University of Kabul, Afghanistan.

$\mathrm{He}$ is Dr Z. Razban, a medically qualified member of the staff of the Department of Medical Biochemistry in that university. He spent two years with us on a WHO Fellowship to gain experience in teaching biochemistry to medical students and also on research in immunological aspects of protein-calorie malnutrition. When he left us in January 1977 he was well trained in a variety of

immunological techniques and had been awarded an MSc based on his research on "Acute phase proteins in children with protein calorie malnutrition" which was also published under this title (Razban et al. $J$. Trop. Med. \& Hyg. 78, 264-266 (1975)).

At that time we understand he was the only doctor in Afghanistan trained in immunology, and on his return he intended to set up an immunological service and to train other doctors and technicians in these techniques, as well as continuing his research and teaching. In order for him to do this successfully it was essential for him to maintain contact with us, and we find it disturbing that for reasons we are unable to discover, this contact has not been maintained. We are certain that $\mathrm{Dr}$ Razban would himself have continued to remain in contact with us, and can only assume that he is prevented from doing so by the authorities in Afghanistan. Yours faithfully,

D.S. JACKSON

University of Manchester, UK

\section{Tumour virus DNA: hazards no longer speculative}

SIR, - The critical response (9 Aug, page 444) by Drs Rowe and Martin to the editorial (7 June, page 461) which called on the US Congress to enact recombinant DNA legislation, appears itself to be somewhat misleading.

While it may have been technically incorrect for the editorial to imply that it was unanticipated by tumour virologists that DNA from tumour viruses can cause tumours, it remains true that no one could have known prior to the Rowe-Martin rìsk assessment experiments (Science 203, 883 and 887; 1979; Israel et al, Science in the press) that tumour virus DNA which has been cleaved with restriction enzymes and spliced into plasmids or lambda phage genomes would retain tumorigenicity.

The importance of this finding is the following: up until now opponents of strict recombinant DNA guidelines and legislation have portrayed fears that an aetiological agent could escape the laboratory in a novel biological form as "purely speculative." However, bacterial plasmids and lambda particles do not customarily carry agents of animal carcinogenesis into the ecological niches occupied by their bacterial hosts. It has now been shown by Rowe, Martin and their coworkers that it is a fairly routine matter to construct plasmids and lambda particles with just such a capability. The fact that these splice products are less effective than ordinary polyoma viruses in promoting tumours in the normal hosts of polyoma is irrelevant: the bacterial route for the dissemination and variation of tumorigenic DNA is a qualitatively new one.

The unlikelihood that the Rowe-Martin experiments released any novel tumorigenic vector into the environment is largely due to the fact that these studies were carried out under P4-EK2 containment protocols. However, under the newly revised NIH Guidelines (Federal Register, January 15, 1979) such tumour virus splicing experiments can now be carried out under P3-EK1 or P2-EK2 protocols.

It should be noted that the efficacies of both the biological safety cabinets used in P2 and P3 experiments, and of the only approved EK2 host, $E$ coli $\chi 1776$, have been recently called into question (Nature, 29 March, page 384; S. Levy, technical report to NIH under risk assessment contract; R. Curtiss III, letter to NIH, May 11, 1979).

Since the hazards of releasing into the ecosystem known aetiological agents in new biological forms can no longer be considered speculative, it should now be unacceptable to denigrate efforts by the NIH Recombinant DNA Advisory Committee, and by the public through its unions and government, to tighten containment through guidelines and legislation that extend to industrial as well as academic laboratories.

Yours faithfully,

Stuart A. Newman

New York Medical College, New York

Meeting on carcinogen

\section{testing is open}

SIR, - In the 23 August issue (page 623) Alastair Hay wrote a short article "Press banned from conference" in which he discussed the status of press invitations to a meeting to evaluate short-term in vitro tests for carcinogenicity. The meeting is open to the public as are all such US Government sponsored meetings, and contrary to his headline and article the press has been neither banned, excluded nor specifically invited.

Investigators of the international programme for the evaluation of short-term tests for carcinogenicity will meet in October to present and discuss their results for testing 42 coded chemical samples. Results from a total of 68 assay system investigators will be presented. The meeting will not be comprised of formal presentations but rather of concurrent work groups. During the first part of the meeting five separate work groups will meet to discuss the raw data from similar bioassays. During the second part of the meeting the participants will be grouped into work groups to evaluate the cumulative test data on individual chemicals. Both phases of the meeting will require tedious analysis of large volumes of raw data and review of details of experimental protocols, neither of which is usually of interest either to the scientific community at large or to the press.

The coordinating committee fully recognise the importance of this study as well as the preparation of a final report for general distribution. It was this recognition that led to the decision to use two different mechanisms to bring this final report to the attention of the scientific and regulatory communities and the public.

Firstly a full account of the study will be published including the section on chemicals reviewed and carcinogenicity data on each chemical, results from individual investigators and an overall summary and evaluation. Secondly, a public information meeting has been planned for 3 December at the National Institutes for Health, Bethesda, to present and discuss the complete results of this study. It is the feeling of the coordinating committee that the six weeks between the October and December meetings will be necessary to make a comprehensive and meaningful evaluation.

It is regrettable that there has been such a misunderstanding concerning press participation at the two meetings planned to bring the international trial to completion. Yours faithfully,

The Coordinating Committee

B A BRIDGES

J ASHBY

I F H PURCHASE

P BROOKES

- Alastair Hay writes: My expert that of other British science journalists, was that we applied to attend the meeting - only to be told that the presence of journalists might inhibit balanced scientific discussion. I subsequently had a letter from one of the organisers, confirming that no journalist was to be invited. If I misunderstood the committee's real intentions, then 1 apologise. 